\title{
Discrete Controlled Pulse Width Modulated Interleaved Boost Converter using Bilinear Transformation Technique
}

\author{
S. Vijayalakshmi ${ }^{1}$, K. Geetha ${ }^{2}$, R. Shenbagalakshmi ${ }^{3}$ and A. Joshi ${ }^{4}$ \\ ${ }^{1 ; 3}$ Dept. of EEE, ${ }^{2 ; 4}$ Dept. of CSE \\ Sarantahan College of Engineering, Anna University, Tiruchirappalli, SASTRA University, Thanjavore \\ Sinhgad Institute of Technology, Pune, India \\ National Institute of Technology, Tiruchirappalli \\ \{bksviji@gmail.com,geethavalavan@gmail.com, lakshmi amrith@yahoo.com, amitjoshi233@gmail.com\}
}

\begin{abstract}
In this work, time domain based discrete controlled Pulse Width Modulated Interleaved Boost converter has been formulated. To achieve the desired closed loop response of the system controller, precise information about the open loop response is vital. In Industries, discrete controller is preferred than other controller, as it will not demand analytical model of the system that has to be controlled. The proposed controller is used to improve the dynamic performance of the Interleaved Boost Converter by achieving a robust output voltage against varying load disturbances, fluctuations in input voltage and deviations in circuit components. The discrete controller is implemented experimentally and the observed results substantiate better mapping between the design goals and the experimentally identified response.
\end{abstract}

Keywords: Interleaved Boost converter (IBC), Discrete PID controller, Analog to Digital conversion (ADC), Digital to Analog Conversion (DAC), Digital Pulse Width Modulation (DPWM).

\section{Introduction}

DC-DC power converters finds its significance in various applications namely PV applications, inverters, battery chargers and Switched Mode Power Supplies. In high power applications, it is impossible for a single switch (Boost) to tolerate either voltage or current stress. For larger current rating an Interleaved Boost Converter (IBC) is the foremost choice to avoid current stress in the main switch to part of the input current is diverted to the other switch. It has the merit of establishing of high output voltage, high power factor, improved efficiency and fewer harmonic as mentioned in [1], [2]. The limitations in the soft switching can be tackled by means of interleaved converters [3]. The proposed interleaved boost converter has less input ripple current, reduced $I^{2} \mathrm{R}$ losses with lower rating of the switch and provides increased system reliability.

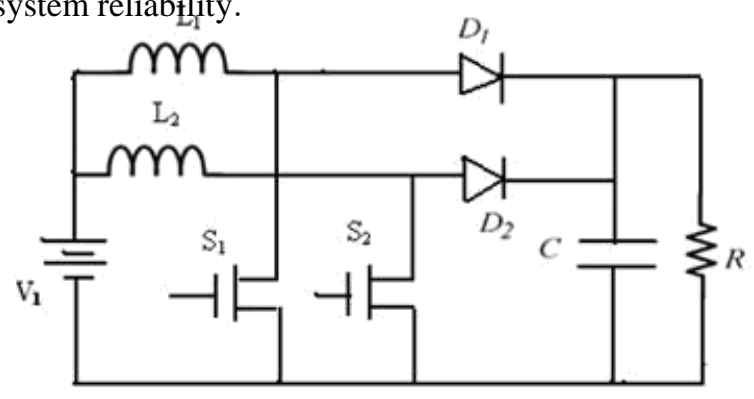

Fig. 1. Power stage of interleaved boost converter

The purpose of Discrete Proportional, Integral, and Differential (PID) controller is, to capture a tight voltage regulation, robustness, fast switching with enhanced transient characteristic in IBC. In the proposed controller,

B. Iyer, S. Nalbalwar and R. Pawade (Eds.)

ICCASP/ICMMD-2016. Advances in Intelligent Systems Research.

Vol. 137, Pp. 825-833.

(C) 2017- The authors. Published by Atlantis Press

This is an open access article under the CC BY-NC license (http://creativecommons.org/licens)es/by-nc/4). 
important parameters namely settling time, rise time and peak overshoot are initialized at a low value. The controller output is free from ripple voltage without steady state error.

The proposed controller also does not take much time to respond the output voltage for variations in the reference voltage.

\section{Design of Interleaved Boost Converter}

Conventional two phase IBC is shown in Fig.1 The summation of the two in-ductor currents are fed as input current to the converter, the inductor ripple currents are set out of phase so that they can cancel each other and thereby minimizing the total input ripple current in the converter. The relationship be-tween the input voltages $\left(\mathrm{V}_{1}\right)$ the output voltage $\left(\mathrm{V}_{\mathrm{o}}\right)$ cited in [4] [5] is given as

$$
=\frac{1}{1-}
$$

The values of $L_{1}, L_{2}$ and $C$ of this converter [6] is given by equations (2) and (3)

$$
\begin{aligned}
& { }_{1}=\mathrm{L}_{2}=\frac{1 \mathrm{~d}}{\mathrm{f} \Delta \mathrm{I}} \\
& \mathrm{C}=\frac{\mathrm{I}_{\mathrm{o}} \mathrm{k}}{\mathrm{f} \Delta \mathrm{V}_{\mathrm{c}}}
\end{aligned}
$$

Where $\mathrm{L}_{1}, \mathrm{~L}_{2}$ are the magnetizing inductance, $\mathrm{C}$ is the output capacitor, $\mathrm{d}$ is the duty cycle, $\mathrm{I}$ is the output ripple current, $\mathrm{V}_{\mathrm{c}}$ is the output ripple voltage. By using the equations 1,2 and 3 , and for the input voltage $\mathrm{V}_{1}=12 \mathrm{~V}$, Switching frequency $\mathrm{f}=100 \mathrm{KHz}$, duty cycle $\mathrm{k}=60 \%$, the expected output power.

$\mathrm{P}_{\mathrm{o}}=50 \mathrm{~W}$, voltage $\mathrm{V}_{\mathrm{o}}=30 \mathrm{~V}$, current $\mathrm{I}_{\mathrm{o}}=1: 67 \mathrm{~A}$, inductance $\mathrm{L}_{1}=\mathrm{L}_{2}=60 \mu \mathrm{H}$, and capacitance value $\mathrm{C}=330 \mu \mathrm{F}$ have been obtained respectively.

\section{Modeling of Interleaved Boost Converter}

IBC can be modeled to operate with continuous current mode operation. For modeling of nonlinear Pulse Width Modulation (PWM) converter state space averaging method has been identified as more appropriate method. The switching of nonlinear system depends upon the duty ratios. The control signal depends upon the voltage, current and duty ratio. The state space average method of Interleaved Boost converter at resistive load is given as:

$$
\cdot=+1
$$

Where $\mathrm{x}$ refers to the state vector matrix, $\mathrm{A}$ is the state coefficient matrix, $\mathrm{B}$ is the source coefficient matrix, $\mathrm{d}$ is the duty cycle and it is a function of $\mathrm{x}$ and $\mathrm{V}_{1}$ in the feedback system. The state coefficient matrix $\mathrm{A}$ and $\mathrm{B}$ are obtained from the equations $5 \& 6$

$$
\begin{aligned}
& =1+(1-) 2 \\
& =1+(1-) 2
\end{aligned}
$$

In Continuous Current Mode, by means of pole-zero cancellation method stability problem can be solved. Diode $\mathrm{D}_{1}$ and $D_{2}$ are continuously retained in a complementary state with the switches $S_{1}$ and $S_{2}$ respectively. When $S_{1}$ is turned $\mathrm{ON}, \mathrm{D}_{1}$ is turned $\mathrm{OFF}$ and vice versa and $\mathrm{S}_{2}$ is turned $\mathrm{ON}, \mathrm{D}_{2}$ is turned OFF vice versa. It can be operated in four modes and the state equations are presented below:

$\begin{array}{ll}\text { 1. } & \text { Mode } 1: S_{1} \text { and } S_{2} \text { is turn ON } \\ \text { 2. } & \text { Mode } 2: S_{1} \text { is } O N \text { and } S_{2} \text { is OFF } \\ \text { 3. } & \text { Mode } 3: S_{1} \text { is } O N \text { and } S_{2} \text { is ON } \\ \text { 4. } & \text { Mode 4: } S_{1} \text { is OFF and } S_{2} \text { is ON }\end{array}$


From the above modes of operation, obtained A1, A2, A3, \& A4 and B1, B2, B3 \& B4 are given in equations 7 and 8

$$
\begin{aligned}
& 1=3=\left[\begin{array}{ccc}
0 & 0 & 0 \\
0 & 0 & 0 \\
0 & 0 & \underline{-1}
\end{array}\right], 2=\left[\begin{array}{ccc}
0 & 0 & 0 \\
0 & 0 & \frac{-1}{2} \\
0 & \underline{-1} & \underline{-1}
\end{array}\right], 4=\left[\begin{array}{ccc}
0 & 0 & \frac{-1}{2} \\
0 & 0 & 0 \\
\frac{-1}{-} & 0 & \frac{-1}{-}
\end{array}\right] \\
& 1=2=3=4=\left[\begin{array}{c}
\frac{1}{1} \\
\frac{1}{2} \\
0
\end{array}\right] \\
& \text { Hence [] }=\left[\begin{array}{lll}
0 & 0 & \frac{-1}{1} \\
0 & 0 & \frac{-1}{2} \\
1 & 1 & \frac{-1}{-}
\end{array}\right],=\left[\begin{array}{c}
\frac{21+2}{1} \\
\frac{21+2}{2} \\
0
\end{array}\right]=\left[\begin{array}{lll}
0 & 0 & 1
\end{array}\right][h]
\end{aligned}
$$

The transfer function tf $(\mathrm{G}(\mathrm{s}))$ [7] of the IBC can be obtained from the equations 7, 8, 9 and the derived form is given in equation 10 .

$$
=\frac{\left(1.364 * 10^{-12}\right)^{2}-\left(4.04 * 10^{6}\right) s-5.46 * 10^{-7}}{3+1.683^{2}-\left(1.616 * 10^{6}\right)+1.222 * 10^{-7}}
$$

\section{Analog PID controller design}

A PID controller is usually referred as three term controller [8] [9]. The letters PI and D stands for P - Proportional, I - Integral, and D - Derivative. The basic form of transfer function for the PID controller is given in equation 11

$0=\left(1+\frac{1}{+}+\right)$

Where $K_{P}$ is the Proportional gain, $T_{I}$ is the Integral time constant, $T_{D}$ is the Derivative time constant, and $C(S)$ is the Analog PID controller equation. Steps to design Analog PID controller is mentioned below:

- By using transfer function $\mathrm{G}(\mathrm{S})$ and unity feedback function $\mathrm{H}(\mathrm{S})$, obtain the characteristic equation $1+\mathrm{G}(\mathrm{S}) \mathrm{H}(\mathrm{S})$, where $\mathrm{G}(\mathrm{S})$ denotes the transfer function of the Interleaved Boost converter and $\mathrm{H}(\mathrm{S})$ represents the unity feedback value.

- Using rouths' stability criterion, find the range of stability $\mathrm{K}$ for the men-tioned characteristic equation.

- Consider the critical gain $\mathrm{K}_{\mathrm{cr}}$, which is equal to the value of $\mathrm{K}$. Obtain the frequency of the sustained oscillations Pcr by taking $\mathrm{S}=\mathrm{j} \omega_{\mathrm{cr}}$ in the characteristic equation.

- The critical period Pcr is obtained by using the relation, $=\stackrel{2}{-}$

- Ziegler-Nichols method is adopted for determining the values of the proportional gain $\mathrm{K}_{\mathrm{P}}$, integral time constant $T_{I}$ and derivative time constant $T_{D}$.

The Analog PID controller equation and designed controller transfer function for IBC are given equations 12, 13 and 14

$$
\begin{gathered}
O=0.6\left(1+\frac{1}{0.5 \mathrm{~S}}+0.125 \mathrm{~S}\right) \\
O=0.001\left(1+\frac{1}{2.14310^{-6}}+5.3610^{-7}\right) \\
()=\underline{116.66^{2}+0.001+466.6}
\end{gathered}
$$




\section{Design of Discrete Controller}

Discrete controllers are more flexible, integratable, reliable, cost effective, and less susceptible to noise and drift and hence more desirable for all types of power converters [10] [11] [12] [13] [14] [15]. The time domain analog PID controller transfer function Equation (14) is transformed into the Discrete PID time domain using bilinear transformation technique. To approximate analog PID controller into Discrete PID controller, bilinear transformation technique is used and is given as: [4] [8] [16].

$$
\begin{aligned}
& \quad=\frac{O}{O}=\left[+\frac{+1}{2-1}+\frac{-1}{-1}\right] \\
& O=\left[\frac{\left(++\frac{2}{2}-\right)^{2}+\left(+\frac{4}{-}\right)}{(-1)}\right] \mathrm{E}(\mathrm{Z})
\end{aligned}
$$

where $K_{P}$ is proportional gain constant, $K_{I}$ is integral gain constant and $K_{D}$ is derivative gain constant. In the Discrete PID controller, $K_{P}$ is used to decrease the rise time, $K_{D}$ to reduce the overshoot and settling time, and $K_{I}$ is used to remove the steady state error. $\mathrm{K}_{\mathrm{D}}=\mathrm{K}_{\mathrm{P}} \mathrm{T}_{\mathrm{D}} ; \mathrm{K}_{\mathrm{I}}=\mathrm{K}_{\mathrm{P}}=\mathrm{T}_{\mathrm{I}} ; \mathrm{T}_{\mathrm{S}}=1 \mu \mathrm{s}$. The Discrete PID controller equation for IBC is derived as:

$\mathrm{U}(\mathrm{Z})=\frac{45.5 \mathrm{Z}^{2}-86.99 \mathrm{Z}+41.5}{\mathrm{Z}(\mathrm{Z}-1)}$

\section{Simulation results and discussion}

The closed loop response of the IBC using the designed value is simulated by Matlab/Simulink software and demonstrated in Fig. 2. The output voltage of the IBC is evaluated against the desired reference voltage. The output of the comparator is the error voltage which is corrected by digital time integral com-pensator. The corrected error signal is again analyzed with the high frequency carrier signal, which produces PWM pulses. The PWM pulse is given to one MOSFET switch and inverted PWM pulse is given to another MOSFET switch.

The Analog PI, Analog PID, Discrete PI controller has also been designed for the above IBC. The values for controller parameters namely settling time, peak overshoot, rise time, steady state error and output ripple voltage have been tabulated in Table 1. The Discrete PID controller has been examined against other controllers. It is obvious from the Table 1 that the Discrete PID controller has better controller specifications than the remaining. It has less rise time, settling time, peak overshoot and steady state error than other controllers as listed in Table 1.

Steady state error observed with load variations are lesser than $1 \%$, little overshoot and no undershoots are apparent. From Table 1, the Discrete PID controller parameters are better than Discrete PI, Analog PI, and Analog PID

controllers. Thus the outcome obtained in Discrete PID controller for IBC is concurrence with the mathematical calculations. Table 1 proves that the digital system outperforms than the Analog controller. Simulation has been carried out by varying the input voltage \& load resistance and the corresponding output voltage, output current,Inductor current (IL1) are shown in Fig. 3 The input voltage is fixed as $10 \mathrm{~V}, 8 \mathrm{~V}, 6 \mathrm{~V}$ and $8 \mathrm{~V}$ during the time instance $0 \mathrm{~s}, 0.025 \mathrm{~s}, 0.05 \mathrm{~s}$, and $0.075 \mathrm{~s}$ respectively. Similarly the load resistance is also set as 30, 26, 22 and 26 during the time instance $0 \mathrm{~s}, 0.025 \mathrm{~s}, 0.05 \mathrm{~s}$, and $0.075 \mathrm{~s}$ respectively. The corresponding output voltage, output current and inductor current are plotted in Fig. 3. The reference voltage is fixed to $16 \mathrm{~V}$, and the resultant output response of IBC illustrates the fixed output voltage regulation. The output response of the controlled converter has neither undershoots nor overshoots, and the steady state error is evident. The simulation result substantiates that the varying input voltage and load resistance has not varied the output voltage. The dynamic performance of the controller has also been verified by varying L1, L2, and C of the IBC, whose consequent output response of the entire system is revealed in Table 2. The inductance L1 and L2 are varied from $10 \mu \mathrm{H}$ to $25 \mu \mathrm{H}$ and the capacitance is varied from $60 \mu \mathrm{F}$ to $90 \mu \mathrm{F}$. These variable converter parameters have not influenced the output voltage.

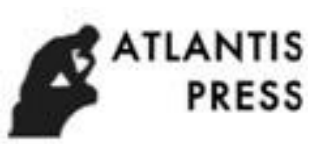




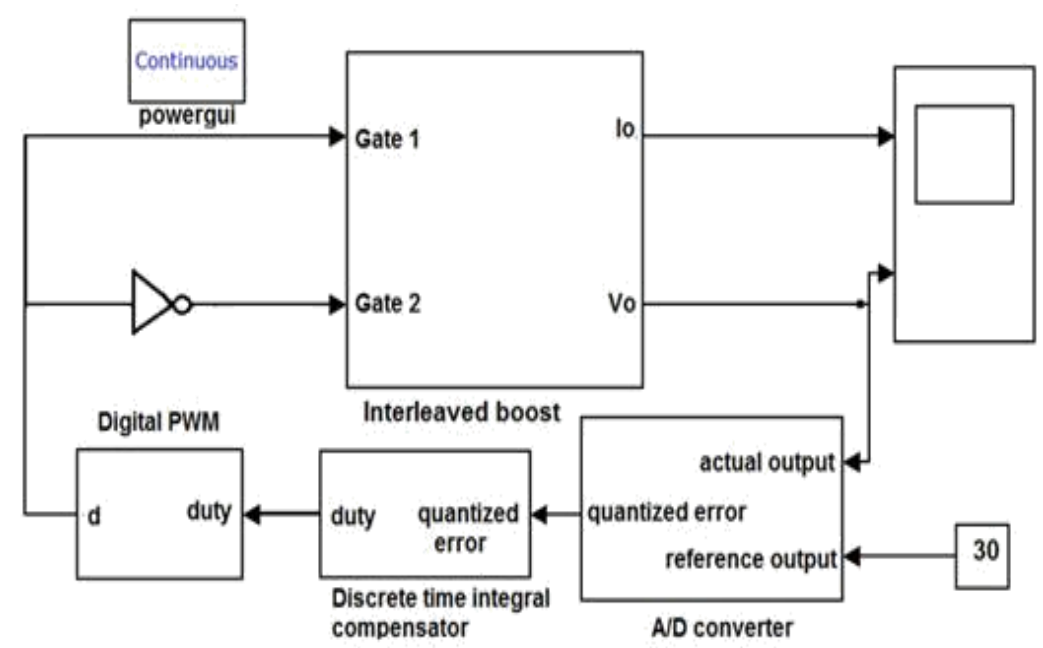

Fig. 2. Matlab/Simulink diagram of Discrete PID based feedback control on IBC

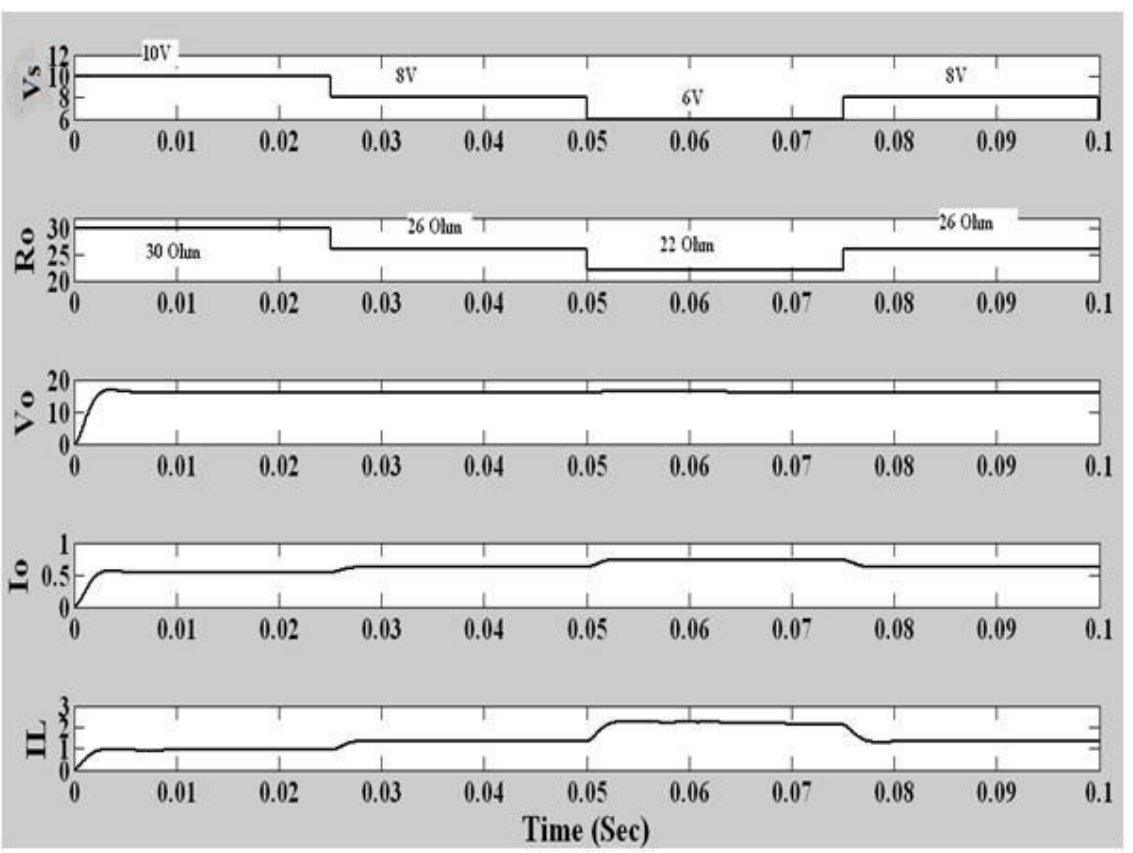

Fig. 3. Output response of the Discrete PID controlled IBC

Table 1. Evaluation of the various controllers for IBC

\begin{tabular}{|l|r|r|r|r|}
\hline Controllers & $\begin{array}{r}\text { Settling Time } \\
(\mathrm{ms})\end{array}$ & $\begin{array}{r}\text { Peak Overshoot } \\
(\%)\end{array}$ & $\begin{array}{r}\text { Rise Time } \\
(\mathrm{ms})\end{array}$ & $\begin{array}{r}\text { Steady state error } \\
(\mathrm{V})\end{array}$ \\
\hline Discrete PID & 2 & 1.5 & 1 & 0.001 \\
\hline Discrete PI & 9 & 4.3 & 2 & 0.07 \\
\hline Analog PID & 24 & 4.43 & 12 & 0.05 \\
\hline Analog PI & 25 & 4.23 & 12 & 0.1 \\
\hline
\end{tabular}


Table 2. Output response of Discrete PID controlled IBC with the variable converter parameters

\begin{tabular}{|l|l|l|l|l|}
\hline $\begin{array}{l}\text { L1 } \\
(\mathrm{H})\end{array}$ & $\begin{array}{l}\mathrm{L} 2 \\
(\mathrm{H})\end{array}$ & $\begin{array}{l}\mathrm{C} \\
(\mathrm{F})\end{array}$ & $\begin{array}{l}\text { Reference Voltage } \\
\left(\mathrm{V}_{\text {ref }}\right)\end{array}$ & $\begin{array}{l}\text { Output Voltage } \\
\left(\mathrm{V}_{0}\right)\end{array}$ \\
\hline 10 & 10 & 76 & 16 & 16.003 \\
\hline & & & & \\
\hline 12 & 12 & 80 & 16 & 16.005 \\
\hline & & & & 16.002 \\
\hline 15 & 15 & 90 & 16 & \\
\hline & & & & 16.001 \\
\hline 20 & 20 & 60 & 16 & \\
\hline & & & & 16.002 \\
\hline 25 & 20 & 65 & 16 & \\
\hline & & & &
\end{tabular}

Table 2 confirms that the Discrete controller is excellent in tracking the reference voltage, when changes occur in inductance L1, L2 and capacitance C values. The converter controlled output do not have any steady state error, undershoot, overshoot and it settles down at a faster rate of about $2 \mathrm{~ms}$ for all the values. Similarly varying the nature of load has not affected the output voltage and is depicted in Table 3. It can also be noticed that the Discrete controlled IBC is capable enough to track the output voltage irrespective of the variations in the load. The given input voltage is $12 \mathrm{~V}$, the load resistance is varied as 26,22 and 30, and the output voltage of the converter is 16.001 $\mathrm{V}, 15.981 \mathrm{~V}$, and $16.003 \mathrm{~V}$ respectively with the reference voltage of $16 \mathrm{~V}$. Then the simulation is carried out for the inductance of $1 \mathrm{mH}$ and $2 \mathrm{mH}$ are added to the resistance of $26 \Omega$, the output voltage is obtained in the order of $16.01 \mathrm{~V}$ and $16.02 \mathrm{~V}$ respectively with the reference voltage of $16 \mathrm{~V}$. The nature of load is changed to RLE, the ideal voltage source of $2 \mathrm{~V}$ and $3 \mathrm{~V}$ is added with the RL load of $26 \Omega, 2 \mathrm{mH}$, the response of the Discrete PID controlled IBC is $16.02 \mathrm{~V}$, and $15.97 \mathrm{~V}$ respectively for the reference voltage of $16 \mathrm{~V}$. From Table 3 it is clear that the Discrete PID controller act in response to the load variations to equate the output voltage against the reference voltage.

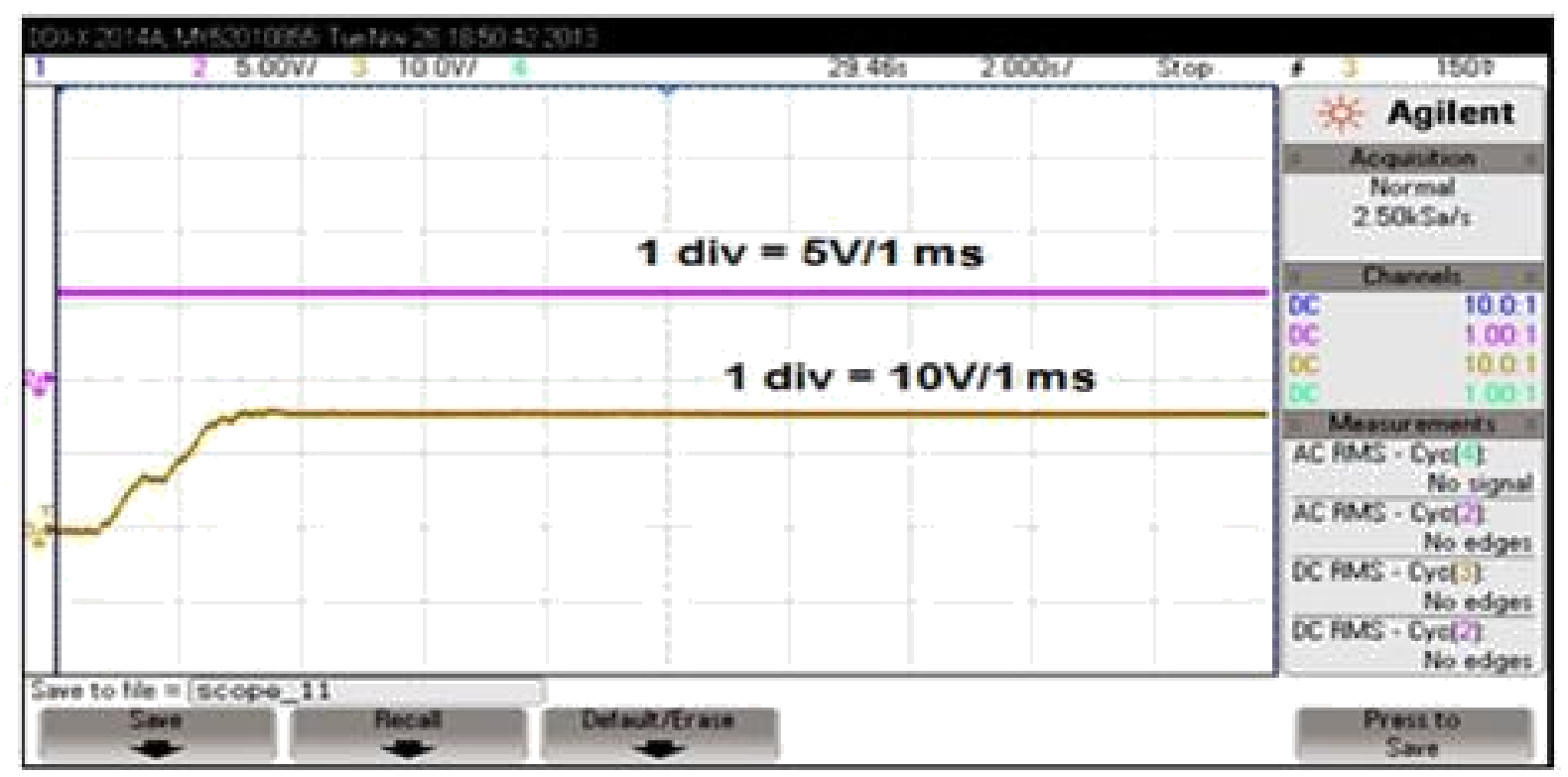

Fig. 4. Output voltage obtained for $6 \mathrm{~V}$ input, $16 \mathrm{~V}$ reference, and 26 load resistance

\section{ATLANTIS


Table 3. Output response of Discrete PID controlled IBC against load variations

\begin{tabular}{|l|l|l|l|l|r|}
\hline \multirow{3}{*}{ Sl.No. } & \multicolumn{3}{|c|}{ Load } & Reference & \multicolumn{1}{l|}{$\begin{array}{l}\text { Output } \\
\text { Voltage (V) }\end{array}$} \\
\cline { 2 - 6 } & $\mathrm{R}(\mathrm{L})$ & $\mathrm{L}(\mathrm{H})$ & $\mathrm{E}(\mathrm{V})$ & & 16.001 \\
\hline \hline 1 & 26 & & - & 16 & 15.981 \\
\hline 2 & 22 & & - & 16 & 16.003 \\
\hline 3 & 30 & & - & 16 & 16.01 \\
\hline 4 & 26 & $1 * 10^{-5}$ & - & 16 & 16.02 \\
\hline 5 & 26 & $210^{-5}$ & 2 & 16 & 15.97 \\
\hline 6 & 26 & $210^{-5}$ & 3 & 16 & \\
\hline
\end{tabular}

\section{Experimental results and discussion}

The IBC with Discrete PID controller has been implemented using LabVIEW that acts like a controller platform. Considering the hardware, a miniaturized prototype of IBC has been designed for $14 \mathrm{~W}$ resistive load. Load voltage was xed at $16 \mathrm{~V}$ to have a reasonable value for load current which worked out for $0.9 \mathrm{~A}$ and hence load resistance of $18 \Omega$ was calculated as per the ohms law. Having fixed all these parameters, the input voltage is set to be $8 \mathrm{~V}$ for interleaved boost converter, as input has to be lower than the output voltage $(16 \mathrm{~V})$. The designed practical values are frequency $\mathrm{f}_{\mathrm{s}}=20 \mathrm{KHz}, \mathrm{V}_{\mathrm{s}}=12 \mathrm{~V}, \mathrm{~L} 1=\mathrm{L} 2=12 \mu \mathrm{H}, \mathrm{C}=63 \mu \mathrm{F}$, load resistor $\mathrm{R}=26 \Omega$, and used components are MOSFET S1, S2 is IRF 840, Diode D1, D2 is 1N 4001, Data Acquisition Cable (DAQ) is NI 9221.

Experimental output voltage response is given in Fig. 4. In a Discrete PID controlled IBC, the given input voltage is $6 \mathrm{~V}$, the reference voltage is $16 \mathrm{~V}$ and the load resistance is $26 \Omega$. Input voltage is taken at channel 2 and the output voltage is taken at channel 3. The output response has $1.2 \mathrm{~ms}$ rise time, $2 \mathrm{~ms}$ settling time and small amount of oscillation occurs initially, neither overshoot nor undershoot has been observed. The output voltage is $16.03 \mathrm{~V}$, hence the steady state error is $0.03 \mathrm{~V}$, which is less than $1 \%$ and hence negligible. Next the given input voltage is set to $12 \mathrm{~V}$ input, reference voltage is $16 \mathrm{~V}$, and the load resistance of $22 \Omega$ for Discrete PID controlled IBC. The output response is depicted in Fig.5 Even though the input voltage and load resistance are changed, the output is always obtained as that of the reference voltage. The output voltage is captured as $16.05 \mathrm{~V}$, rise time and settling time is observed as $5 \mathrm{~ms}$. The results confirm that there is less than $1 \%$ of steady state error $(0.05 \mathrm{~V})$, nil undershoot or overshoot are evident. Hence it can be proved that the experimental results obtained are almost equal to that of simulation results.

The switching pulses next to output voltage for the reference of $16 \mathrm{~V}$ are depicted in Fig. $6 \mathrm{In}$ the experiment, output voltage is taken at channel 1 and PWM pulses are taken at channel 2. The output voltage obtained is $16.02 \mathrm{~V}$, whose corresponding duty cycle ratio obtained is $50.0 \%$. Similarly, for the reference of $20 \mathrm{~V}$, the obtained output voltage is $20.04 \mathrm{~V}$ and the duty cycle ratio is $60.5 \%$ as shown in Fig. 7 The results prove that the change in reference voltage proportionally changes in duty cycle to get the output voltage at the same reference level.

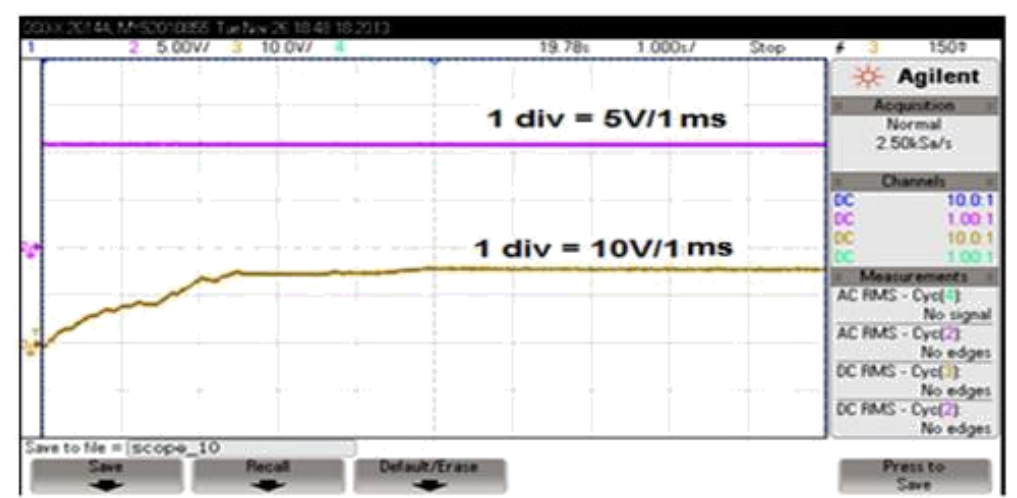

Fig. 5. Output voltage obtained for $12 \mathrm{~V}$ input, $16 \mathrm{~V}$ reference, and $22 \Omega$ load resistance 


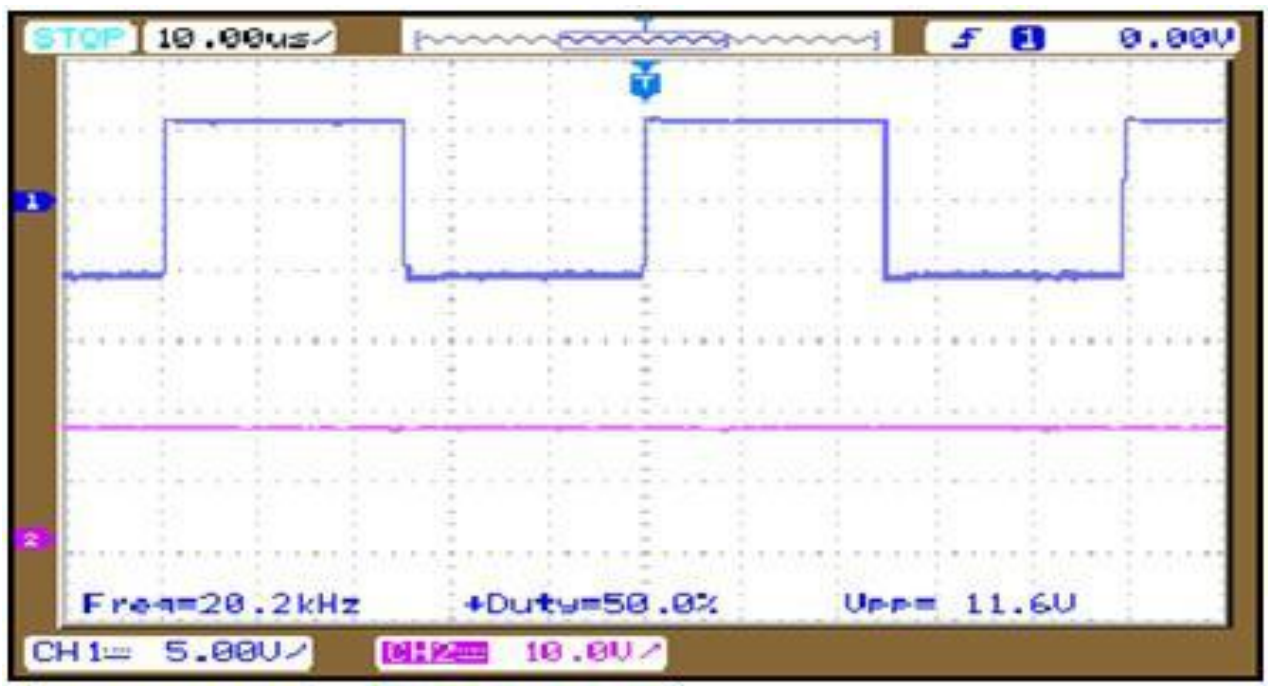

Fig. 6. Duty cycle obtained for $16 \mathrm{~V}$ reference

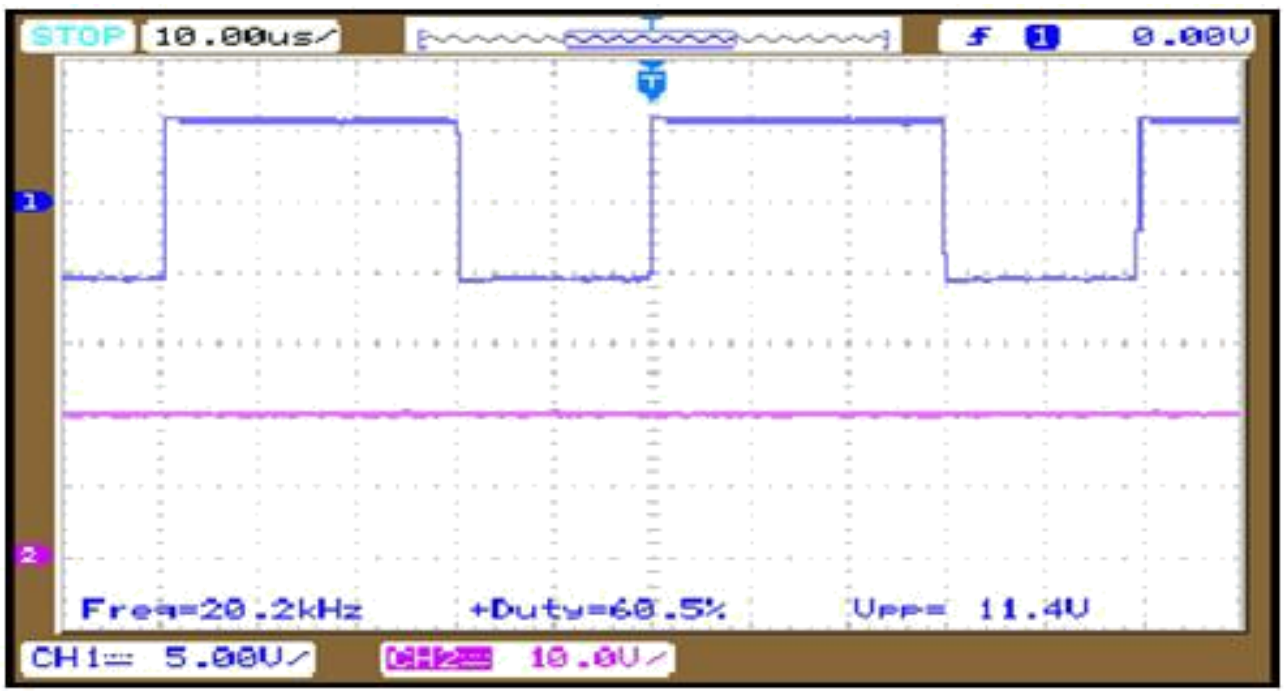

Fig. 7. Duty cycle obtained for $20 \mathrm{~V}$ reference,

\section{Conclusion}

This work proposes an approach for the design of time domain based discrete PID controller for Interleaved Boost Controller and it is implemented using LabVIEW. According to the input error signal, the duty cycle of the switch can be varied to accomplish an enhanced dynamic response. The implementation includes a Discrete PID Controller, which is more suitable for high frequency Switched Mode Power Supply. Simulation, experimental outcomes and comparison with other controllers have been illustrated for the Interleaved Boost converter with discrete PID controller, $50 \mathrm{~W} / 100 \mathrm{KHz}, 12 \mathrm{~V}$ to $30 \mathrm{~V}$ point of load. The response of the system is much faster and it outperforms well for all the possible values of the duty cycle and tunes perfectly for all sort of variations in the load resistance, inductance, capacitance and input voltage. 


\section{References}

[1] Yao-Ching Hsieh, Te-Chin Hsueh, and Hau-Chen Yen. An interleaved boost con-verter with zero-voltage transition. IEEE Transactions on Power Electronics, 24(4):973\{978, 2009.

[2] Carl Ngai-Man Ho, Hannes Breuninger, Sami Pettersson, Gerardo Escobar, Leonardo Augusto Serpa, and Antonio Coccia. Practical design and implemen-tation procedure of an interleaved boost converter using sic diodes for pv applica-tions. IEEE transactions on power electronics, 27(6):2835\{2845, 2012.

[3] Lucio dos Reis Barbosa. A zero-voltage-transition interleaved boost converter and its application to pfc. Advances in Power Electronics, 2, 2011.

[4] Rolf Isermann. Digital control systems. Springer Science \& Business Media, 2013.

[5] Gang Yao, Yan-Qun Shen, Wu-Hua Li, and Xiang-Ning He. A new soft switch-ing circuit for the interleaved boost converters. In Zhongguo Dianji Gongcheng Xuebao(Proc. Chin. Soc. Electr. Eng.), volume 25, pages $65\{69,2005$.

[6] Hiroyuki Kosai, James Sco eld, Seana McNeal, Brett Jordan, and Biswajit Ray. Design and performance evaluation of a 200 c interleaved boost converter. IEEE Transactions on Power Electronics, 28(4):1691\{1699, 2013.

[7] Michael Rice. Digital communications: a discrete-time approach. Pearson Educa-tion India, 2009.

[8] Bruno Robert and Abdelali El Aroudi. Discrete time model of a multi-cell de/dc converter: Non linear approach. Mathematics and Computers in Simula-tion, 71(4):310\{319, 2006.

[9] Simon Ang and Alejandro Oliva. Power-switching converters. CRC press, 2005.

[10] Angel V Peterchev, Jinwen Xiao, and Seth R Sanders. Architecture and ic imple-mentation of a digital vrm controller. IEEE Transactions on Power Electronics, 18(1):356\{364, 2003.

[11] Hao Peng, Aleksandar Prodic, Eduard Alarcon, and Dragan Maksimovic. Modeling of quantization e ects in digitally controlled dc\{dc converters. IEEE Transactions on Power Electronics, 22(1):208\{215, 2007.

[12] Mor Mordechai Peretz and Shmuel Ben-Yaakov. Time-domain design of digital compensators for pwm dcdc converters. IEEE Transactions on Power Electronics, 27(1):284\{293, 2012.

[13] Shuibao Guo, Yanxia Gao, Yanping Xu, Xuefang Lin-Shi, and Bruno Allard. Digi-tal pwm controller for high-frequency low-power dc-dc switching mode power sup-ply. In Power Electronics and Motion Control Conference, 2009. IPEMC'09. IEEE 6th International, pages 1340\{1346. IEEE, 2009.

[14] Subhash Chander, Pramod Agarwal, and Indra Gupta. Auto-tuned, discrete pid controller for dc-dc converter for fast transient response. In India International Conference on Power Electronics 2010 (IICPE2010), pages 1\{7\}. IEEE, 2011.

[15] Benjamin J Patella, Aleksandar Prodic, Art Zirger, and Dragan Maksimovic. High-frequency digital pwm controller ic for dc-dc converters. IEEE Transactions on Power electronics, 18(1):438\{446, 2003.

[16] Charles L Phillips and H Troy Nagle. Digital control system analysis and design. Prentice Hall Press, 2007. 